\title{
Overview of exotic pest and disease notifications 2015-2017
}

\author{
K.M. Hofer and M.S. Bullians
}

Ministry for Primary Industries, PO Box 2095, Auckland

Corresponding author: katharina.hofer@mpi.govt.nz

Early detection of newly arrived exotic plant pests and diseases is critical to protect New Zealand's environment and agriculture. For that purpose, the Ministry for Primary Industries (MPI) conducts active surveillance of numerous high risk organisms, such as fruit flies or gypsy moth, via specific targeted surveillance programmes.

In addition, MPI utilises passive surveillance to enable early detection and reporting of exotic pests and diseases. Members of the public, industry groups, plant health professionals, and diagnostic laboratories report detections of suspected exotic pests and diseases via the "exotic pest and disease hotline" (0800 80 99 66), which operates 24 hours a day, 7 days a week. Notifications are promptly investigated by MPI and deduced biosecurity risks can thus be addressed using appropriate containment, eradication, or long-term management measures.

An overview of passive surveillance data (2015-2017) is presented, with the focus on notifications and investigations of exotic plant pests and diseases associated with recently imported goods. Particular attention is given to cases dealing with high-risk organisms such as the brown marmorated stink bug (BMSB).

\section{Chinese language publications are important for understanding the likely impact of brown marmorated stink bug to kiwifruit}

\author{
D.A.J. Teulon ${ }^{1,2}$ and B. $\mathrm{Xu}^{1}$
}

\author{
${ }^{1}$ The New Zealand Institute for Plant \& Food Research Ltd, Private Bag 4704, Christchurch, 8140, New Zealand \\ ${ }^{2}$ Better Border Biosecurity (B3), New Zealand (B3nz.org) \\ Corresponding author: David.Teulon@plantandfood.co.nz
}

Brown marmorated stink bug (BMSB) is a polyphagous pest originating from Asia but is now established in North America, Europe and recently South America. It has not established in New Zealand but is considered a significant biosecurity threat. Surprisingly, there is very little accessible information on its potential impact on kiwifruit, one of New Zealand's most important horticulture crops. Articles in Chinese characters ${ }^{1,2,3}$ published in Chinese journals more than a decade ago demonstrate that BMSB is an important kiwifruit pest in China and, therefore, of concern to New Zealand's kiwifruit industry. However, these articles were unknown to the broader BMSB research community until recently. This example reemphasises the importance of searching Chinese databases with Chinese characters, along with standard searches in international databases, to ensure a comprehensive understanding of biosecurity risks to New Zealand.

1. Zhang F, Chen Z, Zhang S. 2000. The occurrence and control of Halyomorpha halys in kiwifruit orchards. Northwest Horticulture 2: 38.

2. Guo X, Shi X. 2003. The biology and integrated management of important kiwifruit pests. China Fruits 1: $45-46$.

3. Feng H. 2007. The occurrence and control of pests in kiwifruit orchards. Northwest Horticulture 12: 22. 